\title{
The Evaluation of the EFL Textbooks Used in the High Schools of Elbasan, Albania
}

\author{
Josilda Papajani \\ University of Tirana, PhD candidate
}

\begin{abstract}
The Albanian Education System is currently undergoing several changes, one of which is the Foreign Languages Curriculum implementation. One of the main External Factors in implementing the EFL curriculum is even the kind of Textbook it is chosen to be used in the EFL teaching and learning process. As long as a book is considered 'food for thought', an EFL textbook could be easily considered as 'a milestone' in the students' education. According to this, choosing the right textbook to teach English to High School students is as important as designing the curriculum itself. It is needed to think about the students' needs, interests, ability and level. Choosing a course book is not a frivolous matter, so it should be made clear what kind of English textbook fits best for the students of the High Schools in Albania. This will come out according to the analyses of what the curriculum asks for, the currently used textbooks, as well as according to the observations among teachers and students in the High Schools of Elbasan, Albania.
\end{abstract}

Keywords: EFL textbook, evaluation, curriculum, high school

\section{The importance of textbook}

It seems that Textbooks are the main sources that can convey the knowledge and information to the learners in an easy and organized way. Cunningsworth (1995), for example, identifies a textbook as a resource in presenting the materials and a source for learners to practice and do the activities. Hutchinson and Torres (1994) argue that the textbooks have a very important and positive role to play in teaching and learning. Sheldon (1988) suggests that "textbooks do not only represent the visible heart of any ELT program, but also offer considerable advantages" (p. 237). The most essential function of a textbook is to motivate students to learn (Mikk, 2000). For Dubin and Olshtain (1986) "the tangible element that gives to a language course face validity to many teachers and learners is the textbook" (p. 167). With regard to the essential aim of the ELT textbooks, Byrd (2001) argues that ELT textbooks include two kinds of information which are: the topic content (e.g., Family, school, etc.) and the linguistic content (e.g., grammar, vocabulary, skills) and they help learners to learn the linguistic content through topic content. In fact, textbooks give learners and teachers enough confidence and security (Cunningsworth, 1995). It is agreed that textbooks are of great value in the processes of teaching and learning (e.g., Cunningsworth, 1995; Haycraft, 1998 ; O'Neill, 1982; Sheldon , 1988; Tanner, 1988). Studies which have been conducted in the area of textbook evaluation show that using textbooks is inevitable. Tyson (1997) expresses that for teachers who do not have enough time for lesson planning especially for inexperienced teachers textbooks are useful tools. For having a useful and effective textbook, evaluation is necessary. According to Robinson (1991) evaluation is the discovery of the value of something for a particular purpose. It is regarded as an interactive process (interaction between teachers, learners, and materials) which includes a profound analysis of the materials used. Evaluation in TESOL situations is a process which is used to collect, analyze and interpret required information (Genesee, 2001). This process enables us to make informed decisions through which student achievement will increase and educational programs will be more successful. Grant (1987) states that although there is no perfect textbook, there is the best textbook that can help teachers and learners. He points out that such a book not only matches the learners' needs, interests, and abilities but suits the teachers' needs and meets the officials' needs also. Textbook evaluation is very important because it not only provides useful information for teachers, but also plans learning settings for students. In this regard, McDonough and Shaw (2003) believe that in two kinds of situations some degree of evaluation is needed. First, it is the situation when teachers are given the choice to adopt or develop their own materials. Second, it is when teachers are consumers and just use the products of other people. This is in line with what Cunningsworth (1995) and Ellis (1997) say that textbook evaluation helps teachers move beyond impressionistic assessments, systematic, and contextual insights into the overall nature of textbook material. They also suggest three different types of material evaluation (i.e., pre-use, in-use, and post-use). Pre-use or predictive evaluation is designed to examine the materials before they are used. In-use evaluation is intended to examine the materials which are currently being used. Post-use or retrospective evaluation is designed to examine the materials after they have 
been used. Mukundan (2009) points out that through retrospective evaluation teachers will be informed about the strengths and weaknesses of the textbook and involved in their own professional development. He further states that in this case teachers' knowledge will be increased and their potential for asking and investigating will be enhanced.

The writer of the paper will examine the materials that are, in fact, the realization of the process of syllabus design subsumed under the heading of means/ends specification as mentioned above, and will exclude other factors because it is beyond the scope of this current study to include them.

\section{Why evaluating EFL textbooks?}

The reasons for materials evaluation activities are also many and varied. One of the major reasons is the need to adopt new course books. Another reason as Cunningsworth (1995) emphasized is to identify particular strengths and weaknesses in textbooks already in use. Tomlinson (1996) also states that the process of materials evaluation can be seen as a way of developing our understanding of the ways in which it works and, in doing so, of contributing to both acquisition theory and pedagogic practices. It can also be seen as one way of carrying out action research.( p.238). Grant (1987, p.8) claimed (the) 'Perfect book does not exist', yet the aim was to find out the best possible one that will fit and be appropriate to a particular learner group. Sheldon (1988) suggested that textbooks did not only represent the visible heart of any ELT program, but also offer considerable advantages for both students and the teachers when they were being used in ESL/EFL classrooms. Cunnigsworth (1995) argued that textbooks were an effective resource for self-directed learning, an effective source for presentational material, a source of ideas and activities, a reference source for students, a syllabus where they reflected pre-determined learning objectives, and supported for less experienced teachers to gain confidence. In addition to that, Hycroft (1998) stated that one of the primary advantages of using textbooks was that they were psychologically essential for students since their progress and achievement could be measured concretely when they were used. On the other hand, evaluation is universally accepted as an integral part of teaching and learning. It is one of the basic components of any curriculum and plays a pivotal role in determining what learners learn. Rea-Dickins and Germaine (1994) stated that "evaluation is an intrinsic part of teaching and learning" (p.4). Cunningsworth (1995: 7) suggested that the materials selected should reflect [the needs of the learners and the aims, methods and values of the teaching program. One other reason for textbook evaluation is that it can be very useful in teachers" development and professional growth. Ellis (1997) suggested that textbook evaluation helps teachers went beyond impressionistic assessments and it helped them to acquire useful, accurate, systematic and contextual insights into the overall nature of textbook material.

If one accepts the value of textbooks in ELT, then one should be able to trust that they are of an acceptable level of quality, usefulness, and appropriateness for the context and people with whom they are being used. While the literature on the subject of textbook evaluation is not particularly extensive, various writers have suggested ways of helping teachers to be more sophisticated in their evaluative approach, by presenting evaluation 'checklists' based on supposedly generalizable criteria that can be used by both teachers and students in many different situations. Although Sheldon (1988) suggests that no general list of criteria can ever really be applied to all teaching and learning contexts without considerable modification, most of these standardized evaluation checklists contain similar components that can be used as helpful starting points for ELT practitioners in a wide variety of situations. Preeminent theorists in the field of ELT textbook design and analysis, such as Williams (1983), Sheldon (1988), Brown (1995), Cunningsworth (1995) and Harmer (1996) all agree, for instance, that evaluation checklists should have some criteria pertaining to the physical characteristics of textbooks such as layout, organizational, and logistical characteristics. Other important criteria that should be incorporated are those that assess a textbook's methodology, aims, and approaches and the degree to which a set of materials is not only teachable but also fits the needs of the individual teacher's approach as well as the organization's overall curriculum. Moreover, criteria should analyze the specific language, functions, grammar, and skills content that are covered by a particular textbook, as well as the relevance of linguistic items to the prevailing socio-cultural environment. Finally, textbook evaluations should include criteria that pertain to the representation of cultural and gender components, in addition to the extent to which the linguistic items, subjects, content, and topics match up to students' personalities, backgrounds, needs, and interests as well as those of the teacher and/or institution. Cunningsworth (1995) and Ellis (1997) have suggested that there are three different types of material evaluation. They argue that the most common form is probably the 'predictive' or 'pre-use' evaluation that is designed to examine the future or potential performance of a textbook. The other types of textbook evaluation are the 'in-use' evaluation designed to examine material that is currently being used, and the 'retrospective' or 'post-use' (reflective) evaluation of a textbook that has been used in any respected institution. This 
particular study can be classified as the 'retrospective' type of evaluation in which an attempt is made to check the characteristics of the textbooks under study against a collection of criteria proposed by various researchers.

\section{Materials used for the evaluation of the textbooks used in the high schools of Elbasan}

There were browsed approximately ten checklists proposed by different authors and selected thirteen features which were common to most of these checklists to do the evaluation. The following ten EFL/ESL textbook evaluation schemes were consulted to evaluate the EFL textbooks under study.

- Chastain, K. (1971). The Development of Modern Language Skills: Theory to practice (pp. 376-384). Philadelphia. The Center for Curriculum Development, Inc.

- Tucker, C. A. (1975). Evaluating Beginning Textbooks. English Teaching Forum, 13, 355-361.

- Cowles, H. (1976). Textbook, Materials Evaluation: A comprehensive checksheet. Foreign Language Annals, 9 (4), 300 303.

- Daoud, A. \& Celce-Murcia, M. (1979). Selecting and Evaluating a Textbook. In M. Celce-Murcia and L. Mclntosh (Eds.), Teaching English as a second or foreign language (pp. 302-307).Cambridge, MA: Newbury House Publishers.

- Candlin, C.N. \& Breen, M.P. (1979). Evaluating, Adapting and Innovating Language Teaching Materials. In C. Yorio, K. Perkins and J. Schacter (Eds.) On TESOL '79: The learner in focus (pp. 86-108). Washington, D.C.: Teachers of English to Speakers of Other Languages.

- Rivers, W. (1981). Teaching Foreign-Language Skills (pp. 475-483). Chicago: University of Chicago Press.

- Williams, D. (1983). Developing Criteria for Textbook Evaluation. ELT Journal, 37(2), 251-255.

- Sheldon, L. (1988). Evaluating ELT Textbooks and Materials. ELT Journal, 42 (4), 237-246.

- Skierso, A. (1991). Textbook Selection and Evaluation. In M. Celce-Murcia (Ed.), Teaching English as a second or foreign language (pp. 432-453). Boston, MA: Heinle \& Heinle Publishers.

- Ur, P. (1996). A Course in Language Teaching: Practice \& Theory (pp. 184-187). Cambridge: Cambridge University Press.

After a close examination of the checklists, these criteria were found to be most common to all the schemes proposed by the above mentioned materials:

1. Are objectives explicitly laid out in an introduction, and implemented in the material?

2. Good vocabulary explanation and practice.

3. Approaches educationally and socially acceptable to target community.

4. Periodic review and test sections.

5. Appropriate visual materials available.

6. Interesting topics and tasks.

7. Clear instructions.

8. Clear attractive layout, print easy to read.

9. Content clearly organized and graded.

10. Plenty of authentic language.

11. Good grammar presentation and practice.

12. Fluency practice in all four skills.

13. Encourages learners to develop own learning strategies and to become independent in their learning.

There will be viewed in terms of making quick analyses to the textbooks used in the high schools of Elbasan:

- Blockbuster 3 for the $10^{\text {th }}$ grade

- Blockbuster 4 for the $11^{\text {th }}$ grade

- Wishes B2.1 for the $12^{\text {th }}$ grade 
At the beginning of the above mentioned textbooks, there is an introduction that attempts to clarify the intended teaching objectives. The ultimate goals of the curriculum are clarified in the Teacher's Book, as the final objectives of the curriculum in vivid words so that the students know what they are expected to have learnt at the end of the program (long term objectives.) Likewise, the short term objectives are specified in the introduction of each module. It is known what the learners should be able to do to demonstrate that they have achieved the intended objectives at the end of each course, e.g. at the end of each year in the educational program.

The introduction section is present in all the textbooks and it is more or less the same in terms of the objectives that it specifies as the goals of the lessons and the course. Each module is comprised of five lessons and a Culture Corner/Curricular Cut section. All the parts of the Introduction related to objectives specification mainly concern the activities and techniques that the teachers should do.

In sum, the final goals of the EFL program, as well as the behavioral objectives which are aimed at by the curriculum designers, are clear. This is helpful across the different phases of the curriculum i.e. classroom implementation and evaluation.

As a result of the good points mentioned above, there is an acceptable degree of concordance between the objectives set in the introduction of the books for each section of the lessons in the series and their implementation in the material.

\section{Good vocabulary explanation and practice}

The New Words Section is valid only for Blockbuster 3 and 4. There is no list of New Words Section in Wishes B2.1, which is used for the $12^{\text {th }}$ grade students, even if the reading Comprehension sections are full of new vocabulary.

According to the analyses of Blockbuster 3 and 4, there is correspondence between the different senses of the word introduced in the New Words Sections in the end of the textbook and the meanings which are used in the Reading Comprehensions. The contextualization of the new vocabulary in the New Words Sections is well-given.

However, some parts of the New Words Section ignore the fact that a word might have several different meanings. In some cases, the meaning for a particular word is introduced in the New Words Section, which is consistent only with the meaning of the same word used in the Reading Comprehension, and this probably, bewilders the students, who might have another meaning in their mind for the same word.

Some of the new vocabulary, which the authors might have assumed to be more significant in carrying the semantic load of the related sentence, has been included in the margins of the Reading Comprehension passages with some synonyms or definitions. There is always a specific place designed to practice the new words. The inclusion of the vocabulary exercises in each lesson is very useful, so that learners can integrate the new words into their mental lexicon.

There is also a good contextualization of the new vocabulary' in the New Words Sections, where new words are introduced in different sentences: "Americans typically have vacations of about two weeks. Not many Americans go to other countries for their vacations, and those who do generally go to Canada or Mexico." (Blockbuster 3, p.16)

Likewise, there is a balance between the number of new words included in the New Words Sections and those used in the Reading Comprehensions and other sections of the book. These balances persist throughout the book.

\section{Approaches educationally and socially acceptable to target community}

According to White (1988:92) "A complete syllabus specification will include all five aspects: structure, function, situation, topic, skills. The difference between syllabuses will lie in the priority given to each of these aspects."

It seems that the authors of the books have sequenced the linguistic content of the materials according to the structural complexity, starting from less complex structures to more demanding ones. Even the reading passages are selected or probably manipulated so that they reinforce a particular grammatical point included in the grammar section of the books. However, the question of how and in what order the structures must be arranged in a structural syllabus is a controversial issue. Hutchinson and Waters (1987:88) pose the same question as writing, "What assumptions underlie the ordering in the structural syllabus? Does the verb 'to be' come first, because it is easier to learn? If so, in what sense? Structurally, it is the most complex verb in English. Does it come first because it is needed for later structures, for example the present continuous? Is it considered to be conceptually simpler? Alternatively, is the syllabus ordered according to usefulness? 
The verb 'to be' is more useful than, the present simple tense of the verb 'to go'. If we are operating the criterion of usefulness, what context are we referring to? Do we mean usefulness in the outside world or usefulness in the classroom?"

Nevertheless, the personal experience in teaching these books shows that students learn the present perfect tense with less effort than the passive voice. Moreover, they learn the passive voice better if they are introduced to the present perfect earlier. Thus, it could be suggested that the present perfect, which is introduced in Module 6 of Blockbuster 3 , be transposed to Module 5, and the passive be moved to Module 6.

\section{Periodic review and test sections}

There are review exercises at the end of each Module, which are not enough to revise the new items learned in the Module. The tests and review tests at the end of each one of the lessons. It is worth mentioning that the tests are comparable and compatible with the format and the testing methods which are employed in the mid-term and final exams. To compensate the shortcoming of the practical exercises in the textbooks, there are developed supplementary workbooks for each one of the books. Moreover, students have got the possibility to do the Self-Checks which are available at the end of each module. They can check their answers at the end of the textbook.

The final exams of the $12^{\text {th }}$ grade are designed, administered and corrected by state officials and the teachers play no direct roles in these processes. However, the tests are designed according to the textbooks' content.

\section{Clear, attractive layout, print easy to read}

The paper of the books is of very good quality. The books are acceptable regarding clarity and orthographic beauty. However, it is even more appealing with the colorful pictures of real people and real environments used.

\section{Appropriate visual materials available}

Visual materials can be defined as the facilities that can be employed by teachers and learners to enhance language learning in classrooms. They may range from simple hand-made realia, charts and pictures, to electronic and digital materials. For the series in question, there are CD/DVDs and also the required electronic hardware available at schools for teachers and learners.

The content of the dialogues, whose primary goal is assumed to help the users promote their language skills and enhance learning processes, is effectively addressed. For instance, all the films developed for Book 2 of the series, start with vocabulary teaching.

However, the vocabulary in the dialogues is introduced in the orthographic form with sounds and pictures accompanying them. There are designed pictures or some other graphic materials to illustrate the intended meanings of the introduced words. In some other cases, there is provided the pronunciation of the words with some pauses between, to let the learners repeat the words orally.

Another type of listening exercises has been designed to help the learners improve their reading skills. They start with very brief scenes of two or more people with clear verbal interactions, probably with the intention of motivating the learners to activate their related background world knowledge about the topic to be discussed in the reading passage of the books.

There are some problems worthy of mention concerning these sections. Sometimes, the scenes might seem vague and obscure regarding the messages they are trying to communicate. The learners might find it difficult to catch the meaning that the scenes intend to convey. Consequently, different learners are lead to different interpretations of the scenes and therefore distracted from the main theme of the reading passages. Nevertheless, with a bit of creativity on the part of teachers, these sections can be used as a sort of pre-reading activity to motivate the learners to think about what is going to be discussed in the related reading passages. Moreover, another source of difficulty might be the relatively fast rate of speech of the narrator in reading aloud the reading comprehension passages. Due to the nature of written texts, it is more difficult to process them as fast as the texts produced in oral interactions. Written texts include more embedded sentences and more instances of subordination, which results in longer sentences than oral texts. Written texts are thought to have more information density per utterance than oral texts. Consequently, as a result of these factors, plus some others not mentioned here, written discourse requires more mental effort and thus more time to be processed. A slower rate of speech and inclusion of short pauses between the phrases and sentences might be quite helpful in this case. At the same time, 
this can provide the opportunity for the learners to repeat the phrases and sentences they hear to improve their pronunciation.

The dialogues are usually acted out at a normal rate of speech by the actors who seem to be native speakers of English. Again, very fast rate of speech and lack of space for any kind of practice are the problems that are faced in this section. Despite of all these problems, the teachers who want to use them can modify the pace of the work by manually stopping the device and having the learners repeat the sentences spot-check their understanding. However, the practicality of these sections can possibly be enhanced if these modifications are built into them so that less experienced teachers and maybe the learners could make more effective use of them.

\section{Interesting topics and tasks}

The topics of readings vary from factual to anecdotal, and sometimes are funny stories. It is difficult to judge on behalf of the learners whether they are interesting or not for them, and it needs research. Nevertheless, the majority of the topics seem to be attractive to the learners in the EFL classes. The topics were updated to become more congruent with the taste of the new generation which might is a bit different from that of the authors who designed the books at least ten years ago. Nowadays, learners' needs are different from what they used to be and; hence it looks better that are included texts more related to computer games, the internet, and satellite programs. For instance, it is possible to take and adapt some of the texts, words and jargon which are currently used in information technology. It is also possible to include adapted and simplified versions of quotations and sayings of scholars renowned for their wisdom and eloquence in line with higher culturally valued objectives of education such as trustworthiness, sacrifice, courage, punctuality, patience, honesty, etc. The meaning and content of the materials taught in English classes have strong and long lasting effects on the minds of the learners. This is a valuable opportunity if we want to educate them mentally and spiritually. The text "Could you live in the UK?" attracts the students more than the story of "What did Victorians do for fun?". (Blockbuster 3, p.58-59). It should be taken in mind that, as teachers, our professional and social responsibility do not boil down to imparting a handful of factual information concerning the grammar or meaning of a series of words and sentences in our classes; rather it should be taken care of the transfer of cultural values to new generations.

\section{Clear instruction}

Most of the instructions are clear and easy to understand for the learners in the books. Even if the learners might not be familiar with the structures and the lexis used in the instructions, the models given for each group of exercises provide contextual clues for the learners as to what they are expected to do. However, some of the instructions are lacking in the required contextual information and also may be beyond many of the learners' English language proficiency in terms of linguistic complexity. One possible solution might be to use the learners' native language instead of the target language in the instructions, where the learners are not able to understand complex sentences.

\section{Content clearly organized and graded}

Some of the Reading Comprehension texts tend to be more difficult for the learners to understand than others due to their structural complexity. In working with learners from different proficiency levels, it was realized that the learners misunderstood or did not comprehend some parts of the Reading Comprehension texts, especially extracts from Wishes B2.1, because they did not know the meaning of the new words included in them, or simply because those sentences were too complex for them to comprehend. There might be a number of possible factors which render a text difficult or easy to understand. Content of the passage, the background knowledge of the reader, rhetorical organization, information density, number of unfamiliar words, and length and complexity of the sentences in a text are all possible candidates to make a text difficult or easy to understand.

There are different versions of Fog's formula which make use of factors such as number of syllables or words, length of sentences, or the syntactic complexity of sentences. If it is utilized the one which is based on the number of words and sentences, it will be found a logical sequencing of the reading materials in the book, but if it is applied the formula which is sensitive to the number of sentences and number of complex sentences it will be found a differential outcome. On the basis of the latter formula, - i.e. number of words $\div$ number of sentences + (number of compound sentences $\div$ number of sentences) $\times 40$ - the text containing more compound and longer sentences will have greater readability indices indicating more text difficulty. Considering the fact that most of the unknown words in the texts are taught prior to teaching the Reading Comprehension texts in the books, therefore, it is quite plausible to conclude that the number of new words can play no 
major role in making the text difficult or easy to understand for the learners; rather it is the number of longer and more compound and complex sentences that probably determine the difficulty or easiness of the texts. Thus, the authors of Wishes should have used the sentence-complexity-sensitive formula to sequence the Reading Comprehension texts in the series. However, to solve the problem, two solutions are available: the first one is to 're-organize' the texts according to the readability. Moreover, it requires a close reconsideration of the new vocabulary that the transposed texts include. The second solution is to break long and complex sentences down into shorter and less complex ones. This solution has its own particular problems and challenges, too. In many cases it is not possible to break a compound sentence down into its constituent clauses and phrases and assemble them into simple sentences without spoiling the meaning of the original sentence. For example, in Wishes B2.1, there are plenty of compound sentences which are perceived as challenging to the learners. One of the sentences which is used at the very beginning of a paragraph reads: "He goes on to say 'Chasing is extremely dangerous - especially when I started and there were no on-board radars to show us where and when the tornado would hit and no pre-existing chase instructions." (p. 92). As it is seen, it is not so easy to change this sentence into some simpler sentences which convey the same idea or range of meanings. At first glance, it might be concluded that sentence simplification is the least troublesome solution. However, in practice, it proves most challenging.

In sum, the former solution, however strenuous, feels more practical and easier to manage.

10.

Plenty of authentic language

Authenticity is defined as follows by Johnson and Johnson (1999:24): Texts are said to be authentic if they are genuine instances of language use as opposed to exemplars devised specially for language teaching purposes. The question of authenticity emerged as an important issue within communicative language teaching and in relation to notional/functional syllabuses, where emphasis was placed on ensuring that the classroom contained natural language behavior, with content identified as relevant to the learner through the process of needs analysis. There are various other reasons why authenticity may be regarded as important. One is that it presents learners with language exposure similar to that enjoyed by native speakers, including all the characteristics of natural language which may be necessary for the learner properly to interpret texts. In addition, there is motivational attraction for insisting on authentic texts, created as means of communicating content and not for some pedagogic purpose.

If the discussion is based on the definition of authenticity given above, and seen as the degree the materials concord with actual instances of language the learners will encounter in real situations, the materials could be considered as authentic. In fact, the learners' main use of English language will be limited to reading texts and passages they come across in academic contexts in future, if they continue their education at university. In other cases, depending upon the learners' personal needs, their application of their knowledge of English will be limited to other instances of language used in catalogues, manuals or magazines. In few cases, they might need to listen to English programs on satellite TV or other media in their everyday life and, in rare cases, to communicate verbally with a foreigner who speaks English. Considering the fact that the bulk of materials is devoted to reading activities, and some space is given to dialogues to provide opportunities for the learners to practice verbal communication, the materials can, to certain extent, be regarded as authentic.

\section{Good grammar presentation and practice}

Grammar drills occupy the lion's share of each lesson and range from repetition, substitution to transformational ones. They are aimed at providing the learners with oral practice of the intended grammatical points. The oral drills are techniques which were mainly utilized in Audio-Lingual method and similar approaches to second language teaching for various pedagogical purposes one of which was automatization of the grammatical patterns. Automatization can be viewed from two perspectives: One is to develop the ability to give quick and in-time responses to particular verbal stimuli mainly in phatic communion. The second is to develop the ability to process a given piece of information without awareness or attention, making relatively more use of long-term memory, for example, by producing a particular sentence according to the grammatical rules of a language. However, because the so-called standard tests that are usually administered by the officials of the Ministry of Education are almost completely lacking in test items measuring the productive ability of the learners, the teachers, for this or maybe some other reasons, might skip the drills and replace them with the explicit explanation of the rules and formulas underlying the patterns at issue (strong negative washback effect). Frankly speaking, in regular English classes at high schools they are most often disregarded by the majority of the teachers. 
12.

The books have devoted a large proportion of the lessons to materials that primarily aim at developing and enhancing the reading ability of the learners. Considering the idea that the main needs of the learners might be to acquire an acceptable degree of mastery and skill in reading materials written in English, this allocation looks justified.

However, it is explicitly mentioned by the writers of the books how to treat listening comprehension and writing skills. There is a special section in the lessons specifically designed to develop and enhance listening skills in the learners. However, the teachers can probably work on this skill even through having the learners listen to the reading passages read aloud by the teachers or other learners in the classroom. To involve the learners actively and attentively to listen to the passages read aloud, the teacher can ask various comprehension questions at different points or at the end of the listening activity to check their understanding. The speaking skill is also taken into account though indirectly and as a marginal activity. There are certain questions at the end of each reading passage which require the learners to give oral answers.

The last but not the least is the writing skill. If we define the writing skill as the ability to communicate one's thoughts and ideas to a particular person or group of addressees through the orthographic form of a language, it is possible to claim that it is present in every lesson. There are particular exercises of the lessons which are intended to enhance the writing skills of the learners, by assigning writing activities. There are included writing activities in different formats varying from controlled to free writing according to the proficiency levels of the learner groups.

\section{Encourage learners to develop own learning strategies and to become independent in their learning}

It is attempted to familiarize the learners with cognitive and behavioral strategies or, at least, raise their consciousness about learning strategies. Moreover, throughout the lessons learners come up with certain vocabulary learning strategies such as building up semantic trees which relate different words from a common semantic field.

It is believed that learner training is helpful and valuable in pushing our learners toward the intended goals of both the learners themselves and the teachers but, after all, there are a number of unresolved issues to do with the application of learner strategy research to learner training (see Ellis, 1994: 530-533). It is not clear whether the meta-cognitive and cognitive strategies which are unconsciously applied by the good language learners are teachable in a conscious way. In the meantime, it is particularly vague whether strategies are sufficiently generalizable to be used with a range of learners who will themselves be affected by factors such as context, cognitive styles, and proficiency levels. Nor is there adequate evidence that strategy training leads to improvement in language learning outcomes. As McDonough (1995: 172-3) points out, 'although learning strategies and strategy training are very important elements in the teaching/learning process, great care has to be exercised in moving from a descriptive and taxonomic position to an interventionist one.'

In conclusion, regarding the above mentioned criteria, Blockbuster 3,4 and Wishes B2.1, used I the high schools of Elbasan, are considered to be qualified in helping the learners to develop the learning strategies found in good language learners. They are characterized by the principles of the Common European Framework of Reference and develop all four skills through a variety of communicative tasks. It is designed to promote active, holistic and humanistic learning. Key features include:

Vocabulary is introduced in a functional and meaningful context, and practiced through a variety of exercises in order to help students use every-day English correctly.

Situational dialogues in a range of everyday contexts familiarize students with natural language.

A wide variety of reading texts (e.g. e-mails, texts messages, letters, songs, etc.) allow students to practice and develop reading skills.

Discovery techniques are employed (such as Exploring Grammar) to methodically reinforce students' understanding and to help students learn by exploring the language on their own.

Study Skills help students develop strategies which improve learning skills and enable them to become autonomous learners of the language.

Songs and Games in each module allow students to use language in an enjoyable way. 
Writing sections have been carefully designed to ensure the systematic development of students' writing skills through the use of all four language skills.

Culture Corner Sections: Students are provided with cultural information and read about aspects of life in English-speaking countries. Related tasks and creative projects give students the chance to process the information presented and compare it to the culture of their own country.

Curricular Cuts Sections: These enable students to link the theme of the module to a subject on their school curriculum, thus helping them to contextualise the language they have learnt by relating it to their own personal frame of reference.

Progress awareness - Self-assessment: Students learn to record and evaluate their own progress

Workbook \& Grammar Book: The Workbook aims to consolidate the language presented in the Student's Book through a variety of tasks incorporating all four skills. The Grammar Book provides further exploration of the grammar taught in the Student's Book, with detailed theory and practice.

The CD-ROM provides fully autonomous practice and consolidation of learning in all four skills through the state-of-the-art visual, sound and graphic effects and the engaging, fully interactive tasks and games.

\section{References:}

Byrd, p. (2001). Textbook: Evaluation for selection and analysis for implementation. In M. Celce-Murcia (Ed.). Teaching English as a second or foreign language. Boston: Heinle \& Heinle Publishers.

Cunningsworth, A. (1995). Choosing your coursebook. Macmillan: Heinemann

Dubin, F., \& Olshtain, E. (1986). Course design. Developing programmers and materials for language learn

Ellis, R. (1997). The empirical evaluation of language teaching materials.

Dooley, J. \& Evans, V. (2005). Blockbuster 3. London. Express Publishing.

Dooley, J. \& Evans, V. (2005). Blockbuster 4. London. Express Publishing.

Ellis, R. (1997). The empirical evaluation of language teaching materials. ELT Journal, 51 (1), 36 - 41

Evans, V. \& Dooley, J. (2008). Wishes B2.1. London. Express Publishing.

Grant, N. (1987). Making the most of your textbook. London: Longman

Haycraft, J. (1998). An Introduction to English Language Teaching. London: Longman

Hutchinson, T., \& Torres, E. (1994). The textbook as Agent of change. ELT Journal, 48 (4), 315-328

McDonough, J. \& Shaw, C. (2003). Materials and methods in ELT. Oxford: Blackwell

Mukundan, J. (2009). ESL Textbook Evaluation: A composite framework. Köln: Lambert Academic Publishing

Robinson, P.C. (1991). ESP Today. A Practioners' Guide. London, Prentice Hall

Sheldon, L. (1988). Evaluating ELT Textbooks and materials. ELT Journal,42 (4), 237-246

Tomlinson, B. (2001). Materials development. In R. Carter \& D. Nunan (Eds.), The Cambridge guide to teaching to speakers of other languages (pp. 66 -71) Cambridge: Cambridge University Press

Tyson, H. (1997). Overcoming structural barriers to good textbooks. Washington: National Education Goals Panel 